\title{
The Association Between Monocyte Subsets and Cardiometabolic Disorders/Cardiovascular Disease: A Systematic Review and Meta-Analysis
}

\section{OPEN ACCESS}

Edited by:

Tharmarajan Ramprasath,

Georgia State University,

United States

Reviewed by:

Venkata Garikipati,

The Ohio State University,

United States

Stalinraja Maruthamuthu,

University of California, San Francisco,

United States

Zhaoyu Liu,

Sun Yat-sen Memorial Hospital, China

*Correspondence: Connie J. Rogers cjr102@psu.edu

Specialty section:

This article was submitted to Cardiovascular Metabolism,

a section of the journal

Frontiers in Cardiovascular Medicine

Received: 10 December 2020 Accepted: 27 January 2021

Published: 17 February 2021

Citation:

Oh ES, Na M and Rogers CJ (2021) The Association Between Monocyte Subsets and Cardiometabolic Disorders/Cardiovascular Disease: A Systematic Review and Meta-Analysis. Front. Cardiovasc. Med. 8:640124. doi: 10.3389/fcvm.2021.640124

\author{
Ester S. Oh ${ }^{1}$, Muzi $\mathrm{Na}^{1}$ and Connie J. Rogers ${ }^{1,2 *}$ \\ ${ }^{1}$ Department of Nutritional Sciences, The Pennsylvania State University, University Park, PA, United States, ${ }^{2}$ Center for \\ Molecular Immunology and Infectious Disease, Huck Institutes of the Life Sciences, The Pennsylvania State University, \\ University Park, PA, United States
}

Background: Monocyte subsets in humans, i.e., classical (CM), intermediate (IM), and non-classical monocytes (NCM), are thought to differentially contribute to the pathogenesis of atherosclerosis, the leading cause of cardiovascular disease (CVD). However, the association between monocyte subsets and cardiometabolic disorders and CVD is not well-understood. Thus, the aim of the current systematic review and meta-analysis was to evaluate recent findings from clinical studies that examined the association between the distribution of monocyte subsets in subjects with cardiometabolic disorders and CVD compared to healthy controls.

Methods: Articles were systematically searched in CINAHL, PubMed and Cochrane Library. Articles were independently screened and selected by two reviewers. Studies that reported the percentage of each monocyte subset were included in the systematic review and meta-analysis. For the meta-analysis, a random-effects model was used to generate pooled standardized mean differences (SMD) between subjects with cardiometabolic disorders and healthy controls.

Results: A total of 1,693 articles were screened and 27 studies were selected for qualitative analyses. Among them, six studies were included in the meta-analysis. In total, sample size ranged from 22 to 135 and mean or median age from 22 to 70 years old. We found studies that reported higher percentage and number of IM and/or NCM in subjects with cardiometabolic disorders (9 out of 13 studies) and in subjects with CVD (11 out of 15 studies) compared to healthy controls. In the meta-analysis, the percentage of CM was lower [SMD $=-1.21 ; 95 \% \mathrm{Cl}(-1.92,-0.50) ; P=0.0009 ; R^{2}=91 \%$ ] and the percentage of IM [SMD $\left.=0.56 ; 95 \% \mathrm{Cl}(0.23,0.88) ; P=0.0008 ; r^{2}=65 \%\right]$ and $\operatorname{NCM}\left[S M D=1.39 ; 95 \% \mathrm{Cl}(0.59,2.19) ; P=0.0007 ; l^{2}=93 \%\right]$ were higher in subjects with cardiometabolic disorders compared to healthy controls.

Conclusions: Individuals with cardiometabolic disorders and CVD may have a higher percentage of $\mathrm{IM}$ and NCM than healthy controls. Future studies are needed to evaluate the cause and biological significance of this potential altered distribution of monocyte subsets.

Keywords: monocytes, inflammation, cardiometabolic disorder, cardiovascular disease, systematic review 


\section{INTRODUCTION}

In 2015, there were an estimated 422.7 million cases of cardiovascular disease (CVD) worldwide resulting in 17.9 million CVD deaths (1). Among the different types of CVD, coronary heart disease was the leading cause of morbidity globally, followed by hemorrhagic and ischemic stroke, and hypertension $(2,3)$. Atherosclerosis is the dominant cause of coronary heart disease and stroke (4), which are linked to myocardial infarction and heart failure $(5,6)$. Risk factors for CVD such as obesity, hypercholesterolemia, and type 2 diabetes, have proatherogenic effects by accelerating endothelial and vascular smooth muscle dysfunction, vascular infiltration of low-density lipoprotein (LDL), and the production of oxidized LDL in the subendothelial space $(7,8)$. Moreover, many studies have demonstrated a strong association between inflammation and the risk of atherosclerosis and future cardiovascular events (911). Unresolved and/or dysregulated inflammation triggered by the aforementioned cardiometabolic disorders participates in all stages of atherosclerosis via activation of the innate immune system (12), as well as the expression of adhesion molecules on the arterial surface to induce leukocyte adherence and migration into the intima (13). During the development and progression of atherosclerosis, monocytes play a central role in the dynamic interplay between $\mathrm{T}$ lymphocytes, smooth muscle cells, and platelets in the vascular endothelium (14).

Monocytes are one of the key innate immune cells that circulate in the blood, recognize and attack pathogens, and differentiate into monocyte-derived macrophages (15). Human monocytes express varying amounts of the lipopolysaccharide (LPS) receptor (CD14) and the low-affinity Fc receptor III for IgG (CD16) on their cell surface, and are classified as classical $\left(\mathrm{CD} 14^{++} \mathrm{CD}^{-} 6^{-} ; \mathrm{CM}\right)$, intermediate $\left(\mathrm{CD} 14^{++} \mathrm{CD}^{+} 6^{+}\right.$; IM) and non-classical $\left(\mathrm{CD} 14^{+} \mathrm{CD} 16^{++}\right.$; NCM) monocytes (16). Each monocyte subset displays distinct phenotypic and functional properties which is thought to differentially orchestrate key aspects of the inflammatory response (16). CM are reported to have high phagocytic activity featured by the expression of genes that regulate phagocytosis (17). Upon stimulation with LPS, CM primarily release proinflammatory cytokines, including IL-1 $\beta$, IL-6, MCP-1, and TNF- $\alpha(18,19)$. Moreover, CM have the greatest trans-endothelial migration capacity among the three monocyte subsets $(20,21)$. IM are in a transitional state from $\mathrm{CM}$ to NCM and share phenotypic and functional properties of both subsets (16). IM also are reported to contribute to the inflammatory response via the production of proinflammatory cytokines, such as IL- 6 and TNF- $\alpha$, upon LPS stimulation $(18,19)$. IM are attracted to atherosclerotic lesions via their expression of $\mathrm{C}-\mathrm{C}$ chemokine receptor type 5 (CCR5) and are thought to play a role in the pathogenesis of atherosclerosis $(17,22)$. NCM patrol the vascular endothelium for the presence of damaged cells and may have a surveillance role (23-25).

Several recent observational studies highlight the importance of characterizing monocyte subsets and hypothesize that monocyte subsets may play a differential role in the risk and progression of atherosclerosis and $\operatorname{CVD}(26,27)$. However, the relationship between the distribution of human monocyte subsets and the risk of cardiometabolic disorders and/or CVD has not been systematically evaluated. Therefore, the aim of the current review was to summarize and evaluate findings reported in clinical studies that examined changes in the distribution of monocyte subsets in subjects with cardiometabolic disorders (obesity, metabolic syndrome, hypercholesterolemia, and type 2 diabetes) and CVD (atherosclerosis, coronary artery/heart disease, acute/chronic heart failure, acute myocardial infarction, and acute coronary syndrome) compared to healthy controls to determine if an altered distribution of monocyte subsets is associated with the presence of cardiometabolic disorders and/or CVD.

\section{METHODS}

\section{Protocol Registration}

This systematic review was conducted based on the Preferred Reporting Items for Systematic Reviews and Meta-Analysis (PRISMA) statement (28) (Supplementary Table 1), and was registered in PROSPERO (CRD42020155794) prior to screening and selecting articles.

\section{Search Strategy}

A search strategy was developed in collaboration with a health science librarian at the Pennsylvania State University-University Park campus. The search strategy included two groups of terms to reflect the key concepts of cardiometabolic disorders and CVD (population) and monocyte subsets (outcome) in humans in order to compare the distribution of monocyte subsets between healthy subjects and those with cardiometabolic disorders and/or CVD. Detailed search terms, filters and number of results are provided in Supplementary Table 2. The search was conducted using three databases including Cumulative Index for Nursing and Allied Health (CINAHL), Cochrane Central Register of Controlled Trials, and PubMed, and article records were managed in EndNote X8 (Clarivate Analytics). This search was conducted in October 2020.

\section{Inclusion and Exclusion Criteria}

Inclusion and exclusion criteria were established before study selection (Table 1). Eligible studies included adults $\geq 18$ years of age. Eligible studies were cross-sectional, cohort, withinsubject design studies and randomized-controlled trials (data from baseline) that compared the distribution of monocyte subsets between healthy subjects and those with cardiometabolic disorders and/or CVD. Studies were excluded if they lacked a healthy control group. Animal studies, reviews, abstracts, editorials, commentaries and book chapters were excluded.

\section{Study Selection and Data Extraction}

ESO and CJR independently screened articles by titles and abstracts based on inclusion and exclusion criteria. Articles considered potentially relevant by each reviewer were included for full-text review.

Data were extracted by ESO into a standardized spreadsheet and verified by CJR. Extracted data include: first author, publication year, study design, number of participants, 
TABLE 1 | Inclusion and exclusion criteria.

\begin{tabular}{|c|c|c|}
\hline Components & Inclusion criteria & Exclusion criteria \\
\hline Date range & December 1970-October 2020 & - \\
\hline Language range & English only & - \\
\hline Population & Adults ( $\geq 18$ years old) & - \\
\hline Intervention & No intervention & - \\
\hline Control & - & No healthy controls \\
\hline Outcome & $\begin{array}{l}\text { Changes in the distribution, } \\
\text { phenotype and function of } \\
\text { monocyte subsets in humans }\end{array}$ & - \\
\hline Study design & $\begin{array}{l}\text { Study designs that were eligible } \\
\text { for this review includes: } \\
\text { cross-sectional, cohort, } \\
\text { within-subject design studies and } \\
\text { randomized-controlled trials } \\
\text { (baseline data) that compare the } \\
\text { distribution of monocyte subsets } \\
\text { between healthy participants and } \\
\text { those with cardiovascular } \\
\text { risk/diseases }\end{array}$ & Animal studies \\
\hline Publication format & - & $\begin{array}{l}\text { Reviews, conference } \\
\text { abstracts, editorials, } \\
\text { commentaries, and book } \\
\text { chapters }\end{array}$ \\
\hline
\end{tabular}

characteristics of study population (type of cardiometabolic disorders and CVD), sex and mean/median age of participants. The types of cardiometabolic disorders (overweight and obesity, metabolic syndrome, hypercholesterolemia and type 2 diabetes) and CVD (atherosclerosis, coronary artery disease, coronary heart disease, chronic heart failure, acute heart failure, acute myocardial infarction, and acute coronary syndrome) were chosen because of their association with elevated systemic inflammatory mediators $(9,10,12,13)$. The differences in the distribution of monocyte subsets in participants with cardiometabolic disorders or CVD compared to healthy controls were extracted for each included study. For studies that had multiple groups of subjects with different cardiometabolic disorders or CVD compared to healthy controls, the data were extracted for each condition separately.

From articles that reported the percentage of monocyte subsets, data (mean/median, SD/range and $P$-value) were extracted and used for meta-analysis. From articles that reported correlation coefficients between each monocyte subset and clinical parameters including age, BMI, waist circumference, fat mass \%, fasting blood glucose (FBG), HbAlc, fasting insulin, Homeostatic Model Assessment of Insulin Resistance (HOMAIR), triglycerides (TG), total cholesterol (TC), LDL-cholesterol (LDL-C), high-density lipoprotein cholesterol (HDL-C), very low-density lipoprotein (VLDL), and C-reactive protein (CRP), data (correlation coefficients) were extracted and used for metaanalysis of correlation coefficients.

\section{Quality Assessment}

The NIH National Heart, Lung, and Blood Institute (NHLBI) Quality Assessment Tool for Observational Cohort and Crosssectional Studies was used to assess the quality of observational studies (29). The quality was rated as excellent (12-14 points), good (8-11 points), fair (4-7 points), and poor (0-3 points). The Risk Of Bias In Non-randomized Studies of Interventions (ROBINS-I) tool was used to assess the quality of nonrandomized studies (30). ESO and CJR independently assessed the quality of included studies. Any discrepancies were resolved by discussion.

\section{Statistical Analyses of Meta-Analysis}

The mean and SD of the percentage of each monocyte subset from the group with cardiometabolic disorders and the healthy control group were pooled into standardized mean difference and $95 \%$ confidence interval (CI) to evaluate the association between cardiometabolic disorders and the distribution of monocyte subsets. The mean and SD were extracted from articles, and a standard formula was used to derive the mean and SD if data were reported in a different statistical measures (31). For studies that had multiple groups of subjects with different cardiometabolic disorders and/or CVD compared to healthy controls, the data were included separately in the analysis. A meta-analysis evaluating the association between the distribution of monocyte subsets and cardiometabolic disorders was performed with Cochrane Review Manager (RevMan) version 5.3 (32). A random-effects model was used to generate pooled effect estimates allowing for differences of observed outcomes (distribution of each monocyte subset) across studies. The among-study variance (tau-squared, $\left.\tau^{2}\right)$, chi-squared $\left(\chi^{2}\right)$ test and Higgin's $I^{2}$ statistics were used to test for statistical heterogeneity. Statistical significance was accepted at $P<0.05$. Funnel plots were generated with RevMan version 5.3 (32) to examine publication bias of studies included in the meta-analysis (Supplementary Figure 1).

A meta-analysis of correlation coefficients between monocyte subsets and clinical parameters was performed using MedCalc Statistical Software version 19.1.7 (MedCalc Software, Ostend, Belgium; https://www.medcalc.org). A random-effects model was used to provide a more conservative estimate of the correlation between monocyte subsets and clinical parameters. Each study was weighted according to the number of participants included. Higgin's $I^{2}$ statistics were used to test for statistical heterogeneity. Statistical significance was accepted at $P<0.05$.

\section{RESULTS}

\section{Study Selection}

A total of 1,887 articles were identified through database searching, leaving 1,693 articles for title and abstract screening after duplicates were removed (Figure 1). We excluded 1,528 articles according to the inclusion and exclusion criteria (Table 1), leaving 75 articles eligible for a full-text review. Additional 48 publications were removed because they did not meet the criteria, as detailed in Figure 1. As a result, 27 studies were included in the qualitative analyses, which examined the association between cardiometabolic disorders and CVD and the distribution of monocyte subsets. Among the articles, six studies were included in the meta-analysis to evaluate the association 


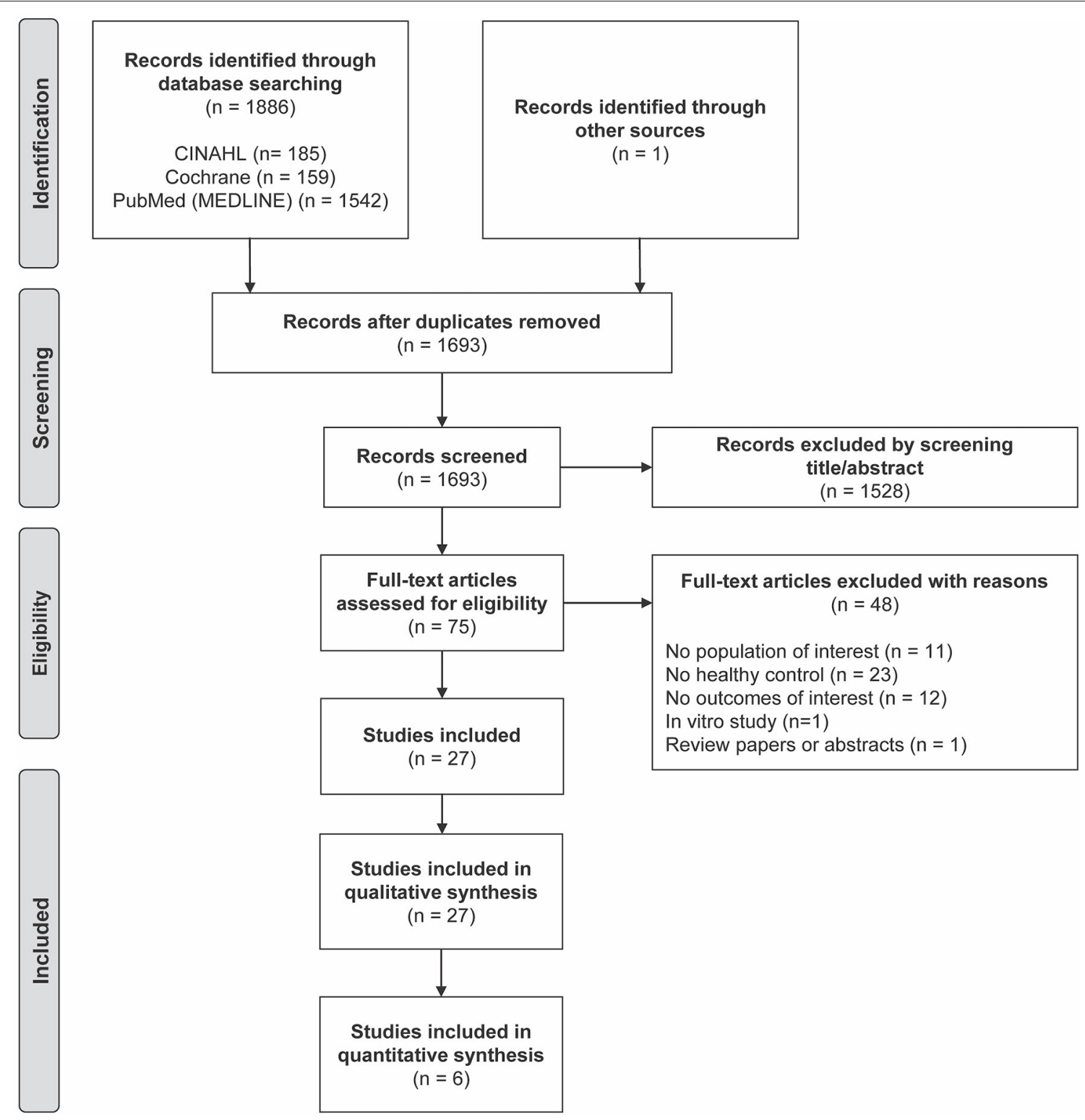

FIGURE 1 | Preferred Reporting Items for Systematic Reviews and Meta-Analyses (PRISMA) flow diagram of included studies.

between cardiometabolic disorders and the distribution of each monocyte subset.

\section{Characteristics of Included Studies}

This review included 26 cross-sectional studies and one withinsubject design study that investigated the association between the cardiometabolic disorders and/or CVD and the distribution of monocyte subsets (Table 2). The types of cardiometabolic disorders included are overweight $(n=2)$, obesity $(n=6)$, metabolic syndrome $(n=2)$, hypercholesterolemia $(n=2)$, and type 2 diabetes $(n=4)$. The types of CVD included are atherosclerosis $(n=3)$, coronary artery disease $(n=6)$, coronary heart disease $(n=1)$, chronic heart failure $(n=2)$, acute heart failure $(n=1)$, acute myocardial infarction $(n=3)$, and acute coronary syndrome $(n=1)$. The sample sizes ranged from 22 to 135 and the mean/median age from 22 to 70 years old.

\section{Quality of Included Studies}

Based on NHLBI Quality Assessment Tool for Observational Cohort and Cross-sectional Studies, $31 \%$ of cross-sectional studies were in good quality and 65\% in fair quality, and $4 \%$ in poor quality (Supplementary Table 3). According to ROBMINSI, the overall risk of a non-randomized study was low, but the risk of bias due to confounding was high (Supplementary Table 4). 
TABLE 2 | Included studies examining the association between the distribution of monocyte subsets and cardiometabolic disorders.

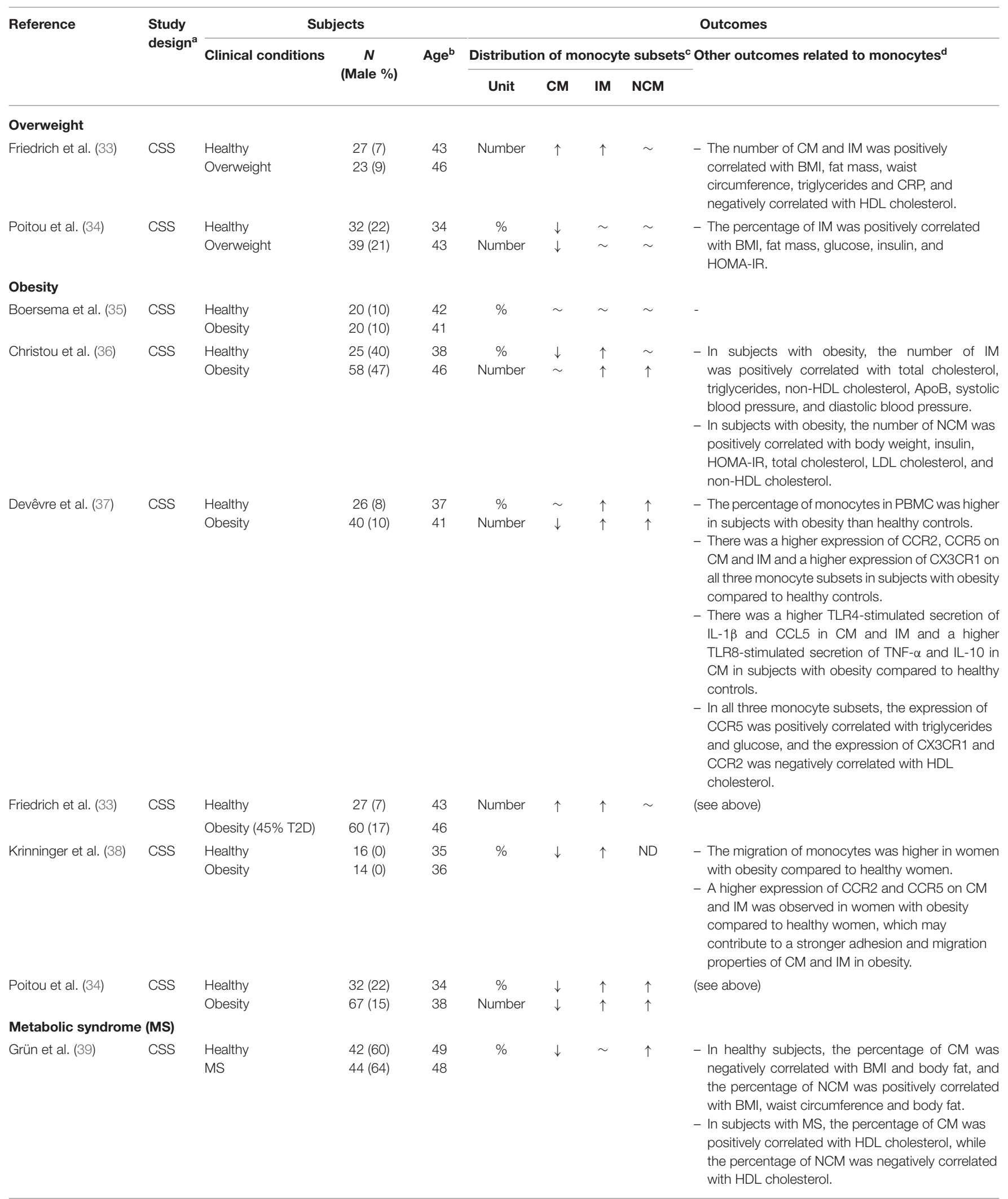


TABLE 2 | Continued

\begin{tabular}{|c|c|c|c|c|c|c|c|c|c|}
\hline \multirow[t]{3}{*}{ Reference } & \multirow{3}{*}{$\begin{array}{l}\text { Study } \\
\text { design }^{a}\end{array}$} & \multicolumn{3}{|c|}{ Subjects } & \multirow{3}{*}{\multicolumn{5}{|c|}{$\begin{array}{l}\text { Outcomes } \\
\text { Other outcomes related to monocytes }^{d}\end{array}$}} \\
\hline & & \multirow[t]{2}{*}{ Clinical conditions } & \multirow{2}{*}{$\underset{\text { (Male \%) }}{N}$} & \multirow[t]{2}{*}{$\mathrm{Age}^{\mathrm{b}}$} & & & & & \\
\hline & & & & & & & & & \\
\hline Khan et al. (40) & WSD & $\begin{array}{l}\text { Healthy } \\
\text { MS }\end{array}$ & $\begin{array}{l}11(82) \\
11(82)\end{array}$ & $\begin{array}{l}43 \\
60\end{array}$ & Number & $\sim$ & $\sim$ & $\uparrow$ & $\begin{array}{l}\text { - The percentage of foamy monocytes was higher in } \\
\text { subjects with MS compared to healthy controls. } \\
\text { - The percentage of foamy monocytes was } \\
\text { positively correlated with circulating triglycerides. }\end{array}$ \\
\hline \multicolumn{10}{|c|}{ Hypercholesterolemia (HC) } \\
\hline Jaipersad et al. (41) & CSS & $\begin{array}{l}\text { Healthy } \\
\mathrm{HC}\end{array}$ & $\begin{array}{l}40(43) \\
40(43)\end{array}$ & $\begin{array}{l}67 \\
67\end{array}$ & Number & $\sim$ & $\sim$ & $\sim$ & $\begin{array}{l}\text { - In subjects with HC, there was a higher IL-6R, } \\
\text { CD49d, and CXCR4 expression on CM, a higher } \\
\text { IL6R and CXCR4 expression on IM, and a higher } \\
\text { CXCR4 expression on NCM compared to healthy } \\
\text { controls. }\end{array}$ \\
\hline Nielsen et al. (42) & CSS & $\begin{array}{l}\text { Healthy } \\
\text { Familial HC }\end{array}$ & $\begin{array}{l}23(35) \\
30(40)\end{array}$ & $\begin{array}{l}47 \\
46\end{array}$ & $\%$ & $\sim$ & $\uparrow$ & $\sim$ & $\begin{array}{l}\text { - The expression of CD36, which involves in the } \\
\text { uptake of oxidized LDL cholesterol, on NCM was } \\
\text { higher in subjects with HC compared to healthy } \\
\text { controls. }\end{array}$ \\
\hline \multicolumn{10}{|l|}{ Type 2 diabetes (T2B) } \\
\hline Poitou et al. (34) & CSS & $\begin{array}{l}\text { Healthy } \\
\text { T2D and Obesity }\end{array}$ & $\begin{array}{l}32(22) \\
38(32)\end{array}$ & $\begin{array}{l}34 \\
50\end{array}$ & $\begin{array}{c}\% \\
\text { Number }\end{array}$ & $\begin{array}{l}\downarrow \\
\downarrow\end{array}$ & $\begin{array}{l}\uparrow \\
\uparrow\end{array}$ & $\begin{array}{l}\uparrow \\
\uparrow\end{array}$ & (see above) \\
\hline Von Scholten et al. (43) & CSS & $\begin{array}{l}\text { Healthy } \\
\text { T2D }\end{array}$ & $\begin{array}{l}16(63) \\
37(70)\end{array}$ & $\begin{array}{l}61 \\
62\end{array}$ & Number & $\sim$ & $\sim$ & $\downarrow$ & $\begin{array}{l}\text { - There was a higher MFI of CD11c, which involves } \\
\text { in monocyte adherence and migration into } \\
\text { atherosclerotic plaques, in patients with T2D } \\
\text { compared to healthy controls. }\end{array}$ \\
\hline Zaharieva et al. (44) & CSS & $\begin{array}{l}\text { Healthy } \\
\text { T2D }\end{array}$ & $\begin{array}{c}7(14) \\
28(36)\end{array}$ & $\begin{array}{l}52 \\
54\end{array}$ & $\%$ & $\downarrow$ & $\sim$ & 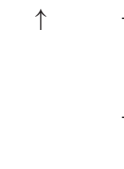 & $\begin{array}{l}\text { - The percentage of IM expressing CD163 was } \\
\text { higher in patients with type } 2 \text { diabetes compared } \\
\text { to healthy controls. } \\
\text { - CD163 expressing IM were positively associated } \\
\text { with waist circumference and glucose. }\end{array}$ \\
\hline $\begin{array}{l}\text { Valtierra-Alvarado et al. } \\
\text { (45) }\end{array}$ & CSS & $\begin{array}{l}\text { Healthy } \\
\text { T2D }\end{array}$ & $\begin{array}{l}27(\mathrm{ND}) \\
28(\mathrm{ND})\end{array}$ & $\begin{array}{l}43 \\
47\end{array}$ & $\%$ & $\downarrow$ & $\sim$ & $\sim$ & $\begin{array}{l}\text { - The percentage CM was negatively correlated with } \\
\text { BMI, HbA1c, and glucose. } \\
\text { - The percentage of NCM was positively correlated } \\
\text { with BMI, HbA1c, and glucose. }\end{array}$ \\
\hline
\end{tabular}

a Study design: CSS; cross-sectional study; WSD, within-subject design.

${ }^{b}$ Age: Age is presented as in the original article (mean or median).

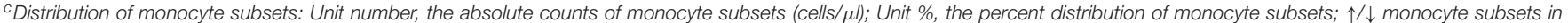
subjects with cardiometabolic disorder are significantly higher/lower compared to healthy controls.

${ }^{d}$ Other outcomes related to monocytes: Outcomes with significant difference are presented.

ApoB, apolipoprotein B; BMI, body mass index; CCL, C-C Motif Chemokine Ligand; CCR, C-C Motif Chemokine Receptor; CM, classical monocytes; CRP, C-reactive protein; CXCR4,

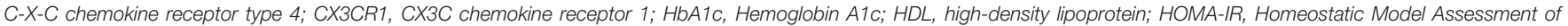

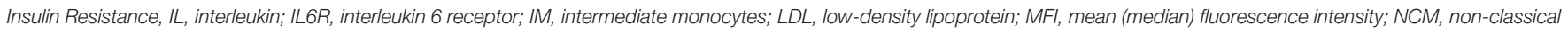
monocytes; PBMC; peripheral blood mononuclear cells; TLR, Toll-like receptor; TNF, Tumor Necrosis Factor.

The possibility of publication bias of the studies included in the meta-analysis is less likely according to the symmetry observed in funnel plots (Supplementary Figure 1).

\section{Cardiometabolic Disorders and Monocyte Subsets (Qualitative Analyses) Overweight and Obesity}

Two studies examined the association between overweight $(25$ $\leq \mathrm{BMI}<30 \mathrm{~kg} / \mathrm{m}^{2}$ ) and the distribution of monocyte subsets. One study reported significantly higher numbers of CM and IM in subjects with overweight compared to healthy controls (33) (Table 2). The other study reported significantly lower percentage and number of $\mathrm{CM}$ but no change in in the percentage and number of IM in subjects with overweight compared to healthy controls (34) (Table 2). Both studies reported no change in the number $(33,34)$ and percentage (34) of NCM in subjects with overweight compared to healthy controls (Table 2).

Six studies examined the association between obesity (BMI $\geq 30 \mathrm{~kg} / \mathrm{m}^{2}$ ) and the distribution of monocyte subsets. Studies quantifying the number of $\mathrm{CM}$ reported inconsistent results with two studies showing a significantly lower number of $\mathrm{CM}$ $(34,37)$ and one study showing a significantly higher number of CM (33) in subjects with obesity compared to healthy controls (Table 2). However, three studies quantifying the percentage of $\mathrm{CM}$ reported a significantly lower percentage of $\mathrm{CM}$ in subjects with obesity compared to healthy subjects $(34,36,38)$ (Table 2). Five studies reported a significantly higher percentage $(34,36-38)$ and number $(33,34,36,37)$ of IM in subjects with 
obesity compared to healthy controls (Table 2). Three studies reported significantly higher percentage $(34,37)$ and number $(34,36,37)$ of NCM in subject with obesity compared to healthy controls (Table 2).

\section{Metabolic Syndrome}

Two studies investigated the association between metabolic syndrome and the distribution of monocyte subsets. Both studies reported significantly higher number (39) and percentage (40) of NCM and no change in the number and percentage of IM $(39,40)$ in subjects with metabolic syndrome compared to healthy controls (Table 2). Among them, one study reported the percentage of CM is significantly lower in subjects with metabolic syndrome compared to healthy controls (39) and the other study reported no significant change (40) (Table 2).

\section{Hypercholesterolemia}

Two studies reported an association between hypercholesterolemia and the distribution of monocyte subsets. One study found the percentage of IM is higher in subjects with hypercholesterolemia compared to healthy controls (42) (Table 2). The other study reported no association between hypercholesterolemia and the percentage of any monocyte subset (41) (Table 2). However, significant phenotypic changes were observed in each monocyte subset, i.e., a higher IL6R, CD49d, and CXCR4 expression on CM; a higher IL6R and CXCR4 expression on IM; a higher CXCR4 expression on NCM (41) (Table 2). Moreover, the number of CM was found to be a significant predictor of carotid stenosis, intima-media thickness and grade 2 neovascularization (41) (Table 2).

\section{Type 2 Diabetes}

Four studies examined the relationship between type 2 diabetes and the distribution of monocyte subsets. Three studies reported that the number (34) and the percentage $(34,44,45)$ of CM are significantly lower, and the number and the percentage of IM (34) and $\operatorname{NCM}(34,44)$ are significantly higher in subjects with type 2 diabetes compared to healthy controls (Table 2). In contrast, one study reported a significantly lower number of NCM in subjects with type 2 diabetes, but also reported a significantly higher mean fluorescence intensity (MFI) of CD11c on NCM in subjects with type 2 diabetes compared to healthy controls (43) (Table 2).

\section{Cardiovascular Disease and Monocyte Subsets (Qualitative Analysis) Atherosclerosis}

Three studies examined the association between atherosclerosis and the distribution of monocyte subsets. All three studies reported that the percentage of IM was significantly higher in patients with atherosclerosis compared to healthy controls (27, 46,47 ) (Table 3). One study reported a higher percentage of CM (46), another study reported a lower percentage of CM (47), and the other study reported no change in the percentage of $\mathrm{CM}$ (27) in patients with atherosclerosis compared to healthy controls (Table 3). There was no significant change in the percentage of NCM in subjects with atherosclerosis compared to healthy controls $(27,46,47)$ (Table 3).

\section{Coronary Artery/Heart Disease}

Six studies examined the association between coronary artery disease and the distribution of monocyte subsets. No change was observed in the number and the percentage of IM in subjects with coronary artery disease compared to healthy controls (41, 4852) (Table 3). Mixed results were reported for CM and NCM. Two studies reported a higher number (41) and percentage (49) of CM, and one study reported a lower percentage of CM (51) in patients with coronary artery disease compared to healthy controls (Table 3). One study reported a lower number and percentage of NCM (49), whereas two studies reported a higher number (41) and percentage (51) of NCM in patients with coronary artery disease compared to healthy controls (Table 3). However, significant phenotypic changes among the monocyte subsets were reported in subjects with coronary artery disease compared to healthy controls, i.e., a higher proportion of monocyte-platelet aggregate (MPA) on all three monocyte subsets (49); a higher IL6R expression on CM and IM (41, 50); a higher TLR4 and Tie2 expression in NCM (41) (Table 3).

One study examined the association between coronary heart disease and the distribution of monocyte subsets. No change was observed in the number of any monocyte subset in patients with coronary heart disease compared to healthy controls (53) (Table 3).

\section{Chronic/Acute Heart Failure}

Two studies examined the association between chronic heart failure and the distribution of monocyte subsets. One study reported a lower percentage of CM (54), while the other study reported a higher number of CM (55) in patients with chronic heart failure compared to healthy controls (Table 3). Both studies reported a higher number (55) and percentage (54) of NCM, and no change in IM in patients with chronic heart failure compared to healthy controls (Table 3).

One study investigated the association between acute heart failure and the distribution of monocyte subsets. The numbers and percentages of IM and NCM were significantly higher in patients with acute heart failure at hospital admission compared to healthy controls (56) (Table 3). This study also reported a lower percentage of $\mathrm{CM}$ and a higher number of $\mathrm{CM}$ in patients with acute heart failure compared to healthy controls (56) (Table 3).

\section{Acute Myocardial Infarction/Acute Coronary Syndrome}

Three studies investigated the association between acute myocardial infarction and the distribution of monocyte subsets. Two studies demonstrated a significantly higher number of CM $(52,53)$, higher number $(52,53)$ and percentage $(52)$ of IM, and a higher percentage of NCM (52) in patients with myocardial infarction compared to healthy controls, when the monocyte subsets were assessed during the first 24-h after primary percutaneous coronary intervention (pPCI) (Table 3). One study examined the distribution of monocyte subsets before pPCI at median time of 4-h after the onset of acute myocardial infarction, and found a lower percentage of CM but no alterations 
TABLE 3 | Included studies examining the association between the distribution of monocyte subsets and cardiovascular diseases.

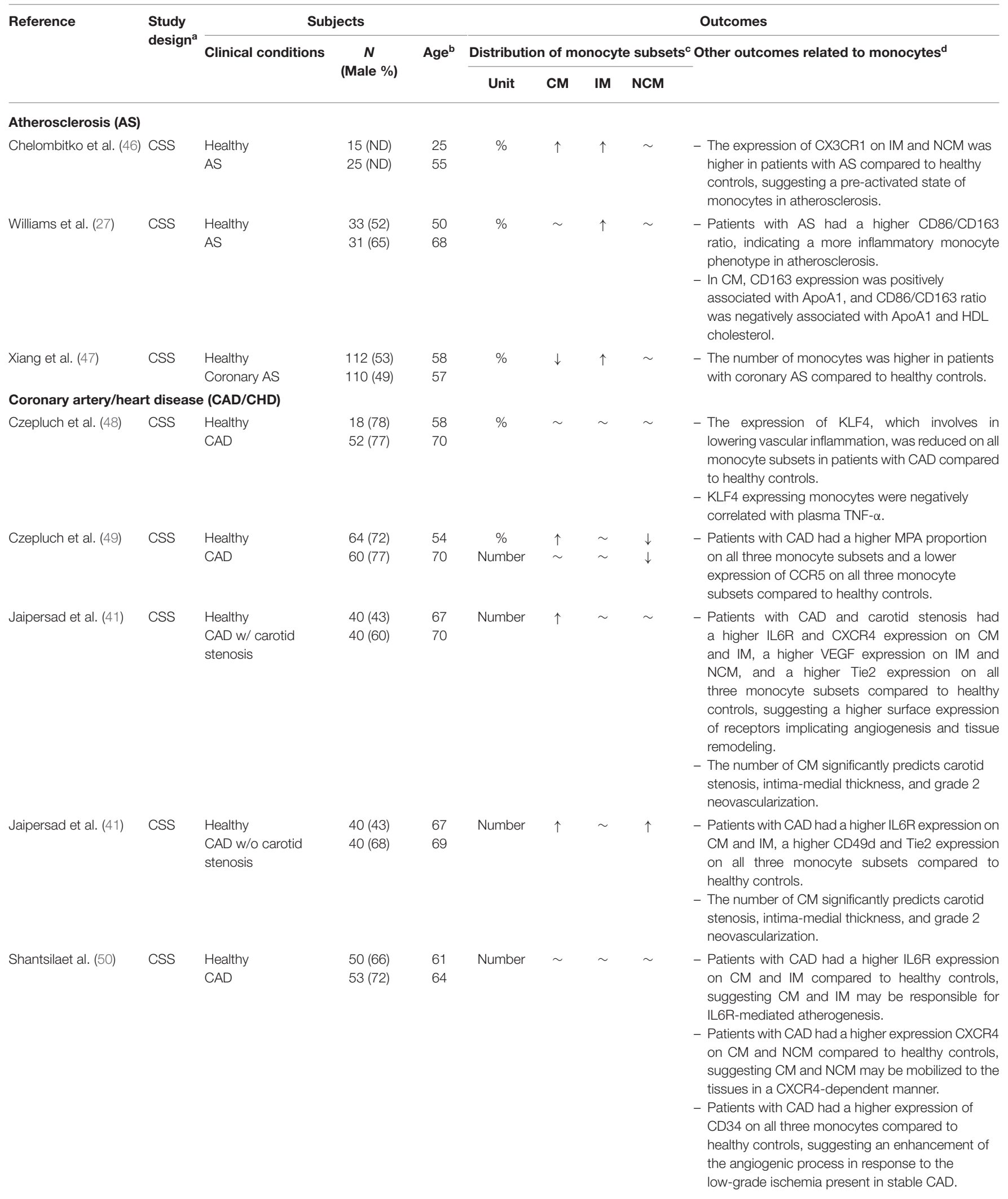


TABLE 3 | Continued

\begin{tabular}{|c|c|c|c|c|c|c|c|c|c|}
\hline \multirow[t]{3}{*}{ Reference } & \multirow{3}{*}{$\begin{array}{l}\text { Study } \\
\text { design }^{\mathrm{a}}\end{array}$} & \multicolumn{3}{|c|}{ Subjects } & \multicolumn{5}{|r|}{ Outcomes } \\
\hline & & \multirow[t]{2}{*}{ Clinical conditions } & \multirow{2}{*}{$\begin{array}{c}N \\
\text { (Male \%) }\end{array}$} & \multirow[t]{2}{*}{ Age $^{b}$} & \multicolumn{5}{|c|}{ Distribution of monocyte subsets ${ }^{c}$ Other outcomes related to monocytes ${ }^{d}$} \\
\hline & & & & & Unit & $\mathbf{C M}$ & IM & NCM & \\
\hline Tallone et al. (51) & cSS & $\begin{array}{l}\text { Healthy } \\
\text { CAD }\end{array}$ & $\begin{array}{l}13(38) \\
14(64)\end{array}$ & $\begin{array}{l}59 \\
60\end{array}$ & $\%$ & $\downarrow$ & $\sim$ & $\uparrow$ & $\begin{array}{l}\text { - Patients with CAD had a higher CCR2 and } \\
\text { CX3CR1 expression on CM, suggesting an } \\
\text { elevated adhesion and accumulation of CM to } \\
\text { vascular endothelium. }\end{array}$ \\
\hline & & CAD & $40(83)$ & 60 & Number & $\sim$ & $\sim$ & $\sim$ & \\
\hline \multirow[t]{2}{*}{ Zhou et al. (53) } & CSS & Healthy & $35(69)$ & 59 & Number & $\sim$ & $\sim$ & $\sim$ & - \\
\hline & & $\mathrm{CHD}$ & $60(68)$ & 61 & & & & & \\
\hline \multicolumn{10}{|c|}{ Chronic/acute heart failure (CHF/AHF) } \\
\hline Amir et al. (54) & CSS & $\begin{array}{l}\text { Healthy } \\
\text { CHF }\end{array}$ & $\begin{array}{l}29(52) \\
59(76)\end{array}$ & $\begin{array}{l}60 \\
58\end{array}$ & $\%$ & $\downarrow$ & $\sim$ & $\uparrow$ & $\begin{array}{l}\text { - Patients with CHF had a higher intracellular IL-13 } \\
\text { concentration in IM compared to healthy controls } \\
\text { and the percentage of IM was positively } \\
\text { correlated with serum IL-13, suggesting that } \\
\text { IL-13 and IM may play a role in the process in } \\
\text { heart failure. }\end{array}$ \\
\hline $\begin{array}{l}\text { Van Craenenbroeck } \\
\text { et al. (55) }\end{array}$ & CSS & $\begin{array}{l}\text { Healthy } \\
\text { CHF }\end{array}$ & $\begin{array}{l}15(60) \\
20(65)\end{array}$ & $\begin{array}{l}44 \\
51\end{array}$ & $\begin{array}{c}\% \\
\text { Number }\end{array}$ & $\tilde{\sim}$ & $\sim$ & $\sim$ & - \\
\hline $\begin{array}{l}\text { Goonewardena et al. } \\
\text { (56) }\end{array}$ & cSS & $\begin{array}{l}\text { Healthy } \\
\text { AHF at admission }\end{array}$ & $\begin{array}{l}11(73) \\
19(79)\end{array}$ & $\begin{array}{l}60 \\
56\end{array}$ & $\begin{array}{c}\% \\
\text { Number }\end{array}$ & $\begin{array}{l}\downarrow \\
\uparrow\end{array}$ & $\begin{array}{l}\uparrow \\
\uparrow\end{array}$ & $\begin{array}{l}\uparrow \\
\uparrow\end{array}$ & $\begin{array}{l}\text { - The number of monocytes was higher in patients } \\
\text { with AHF compared to healthy controls. }\end{array}$ \\
\hline \multicolumn{10}{|c|}{ Acute myocardial infarction (AMI)/Acute coronary syndrome (ACS) } \\
\hline \multirow[t]{2}{*}{ Kazimierczyk et al. (57) } & CSS & Healthy & $18(78)$ & 57 & $\%$ & $\downarrow$ & $\sim$ & $\sim$ & - \\
\hline & & $\begin{array}{l}\text { AMl at admission } \\
\text { (before } \mathrm{pPCl} \\
\text { median time of } 4 \mathrm{~h} \\
\text { after onset) }\end{array}$ & $18(78)$ & 65 & & & & & \\
\hline Tapp et al. (52) & CSS & Healthy & $40(80)$ & 60 & $\%$ & $\sim$ & $\uparrow$ & $\uparrow$ & - \\
\hline
\end{tabular}

\footnotetext{
a Study design: CSS; cross-sectional study.
}

${ }^{b}$ Age: is presented as in the original article (mean or median).

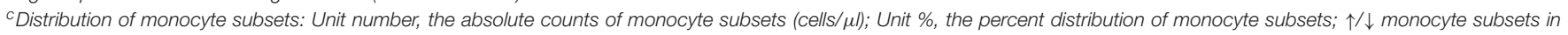
subjects with cardiovascular disease are significantly higher/lower compared to healthy control.

'Other outcomes related to monocytes: Outcomes with significant difference are presented.

ApoA1, apolipoprotein A1; CCR, C-C Motif Chemokine Receptor; CM, classical monocytes; CXCR4, C-X-C chemokine receptor type 4; CX3CR1, CX3C chemokine receptor 1; HDL, high-density lipoprotein; IL, interleukin; IL6R, interleukin 6 receptor; IM, intermediate monocytes; KLF, Krüppel-like factor 4; MPA, monocyte-platelet aggregate; NCM, non-classical

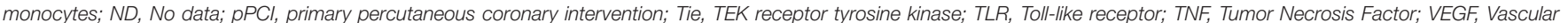
endothelial growth factor. 


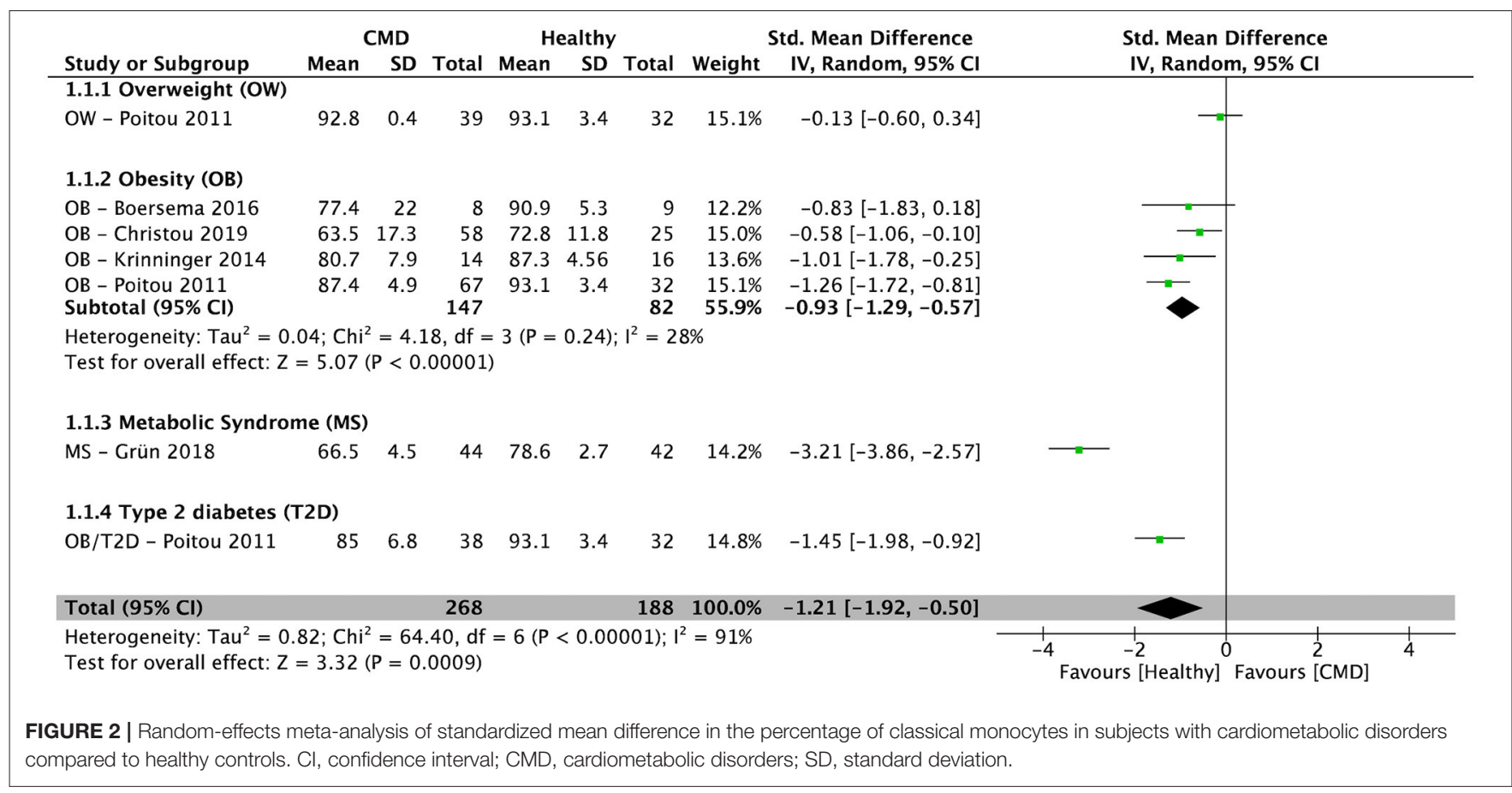

in IM and NCM in patients with acute myocardial infarction compared to healthy subjects (57) (Table 3).

One study examined the association between acute coronary syndrome and the distribution of monocyte subsets. The number and the percentage of CM were higher, the percentage of IM was lower, and the number of NCM was higher in subjects with acute coronary syndrome compared to healthy controls (58) (Table 3).

\section{Cardiometabolic Disorders and Monocyte Subsets (Meta-Analysis)}

After pooling the results from five cross-sectional studies (34$36,38,39$ ), there was a significantly lower percentage of CM in individuals with cardiometabolic disorders (overweight, obesity, metabolic syndrome, and type 2 diabetes) when compared to healthy controls $[\mathrm{SMD}=-1.21 ; 95 \% \mathrm{CI}(-1.92,-0.50) ; P$ $=0.0009 ; I^{2}=91 \%$ ] (Figure 2). In subjects with obesity, the pooled percentage of CM from four cross-sectional studies (34$36,38)$ was significantly lower compared to healthy controls [SMD $=-0.93 ; 95 \% \mathrm{CI}(-1.29,-0.57) ; P<0.00001 ; I^{2}=28 \%$ ] (Figure 2).

After pooling results from six cross-sectional studies (34$36,38,39,42)$, there was a significantly higher percentage of IM in subjects with cardiometabolic disorders compared to healthy controls [SMD $=0.56 ; 95 \% \mathrm{CI}(0.23,0.88) ; P=0.0008 ; I^{2}=65 \%$ ] (Figure 3). In subjects with obesity, the pooled percentage of IM from four cross-sectional studies $(34-36,38)$ was significantly higher compared to healthy controls [SMD $=0.73 ; 95 \% \mathrm{CI}(0.44$, 1.01); $P<0.00001 ; I^{2}=0 \%$ ] (Figure 3).

After pooling results from five cross-sectional studies (34$36,39,42)$, there was a significantly higher percentage of NCM in subjects with cardiometabolic disorders compared to healthy controls $\left[\mathrm{SMD}=1.39 ; 95 \% \mathrm{CI}(0.59,2.19) ; P=0.0007 ; I^{2}=93 \%\right]$
(Figure 4). In subjects with obesity, the pooled percentage of NCM from three cross-sectional studies (34-36) was significantly higher compared to healthy controls [SMD $=0.83 ; 95 \% \mathrm{CI}(0.27$, 1.39); $P=0.003 ; I^{2}=62 \%$ ] (Figure 4).

Six cross-sectional studies report the correlation between each monocyte subset and clinical parameters $(33,34,36,39,44,45)$. There was a positive correlation between the percentage of CM and fat mass $\left[r=0.358 ; 95 \% \mathrm{CI}(0.21,0.49) ; P<0.001, I^{2}=0 \%\right]$ (Supplementary Table 5). The percentage of IM was positively correlated with age $[r=0.204 ; 95 \%$ CI $(0.01,0.39) ; P=0.043$, $\left.I^{2}=0 \%\right]$, BMI $\left[r=0.225 ; 95 \%\right.$ CI $(0.001,0.43) ; P=0.049, I^{2}$ $=81 \%]$, fat mass $\left[r=0.311 ; 95 \% \mathrm{CI}(0.08,0.51) ; P=0.009, I^{2}\right.$ $=75 \%]$, FBG $\left[r=0.149 ; 95 \%\right.$ CI $(0.04,0.25) ; P=0.006, I^{2}=$ $0 \%]$, fasting insulin $[r=0.227 ; 95 \%$ CI $(0.11,0.34) ; P<0.001$, $\left.I^{2}=0 \%\right]$, HOMA-IR $[r=0.236$; 95\% CI $(0.12,0.35) ; P<0.001$, $\left.I^{2}=0 \%\right]$, TG $\left[r=0.288 ; 95 \%\right.$ CI $(0.12,0.44) ; P=0.001, I^{2}=$ $52 \%]$, and CRP $\left[r=0.285 ; 95 \%\right.$ CI $(0.13,0.43) ; P=0.001, I^{2}$ $=53 \%$ ] (Supplementary Table 5). The percentage of NCM was positively correlated with BMI $[r=0.257 ; 95 \% \mathrm{CI}(0.02,0.47) ; P$ $\left.=0.04, I^{2}=77 \%\right]$, fasting insulin $[r=0.338 ; 95 \% \mathrm{CI}(0.09,0.55)$; $\left.P=0.008, I^{2}=72 \%\right]$, and HOMA-IR $[r=0.325 ; 95 \%$ CI $(0.06$, $0.55) ; P=0.018, I^{2}=76 \%$, and negatively correlated with HDLC $\left[r=-0.260 ; 95 \%\right.$ CI $\left.(-0.45,-0.06) ; P=0.013, I^{2}=69 \%\right]$ (Supplementary Table 5).

\section{DISCUSSION}

To our knowledge, this is the first systematic review and meta-analysis that has evaluated the evidence linking either cardiometabolic disorders or CVD with the distribution of monocyte subsets. We found that 9 out of 13 studies demonstrated a higher percentage and number of IM 


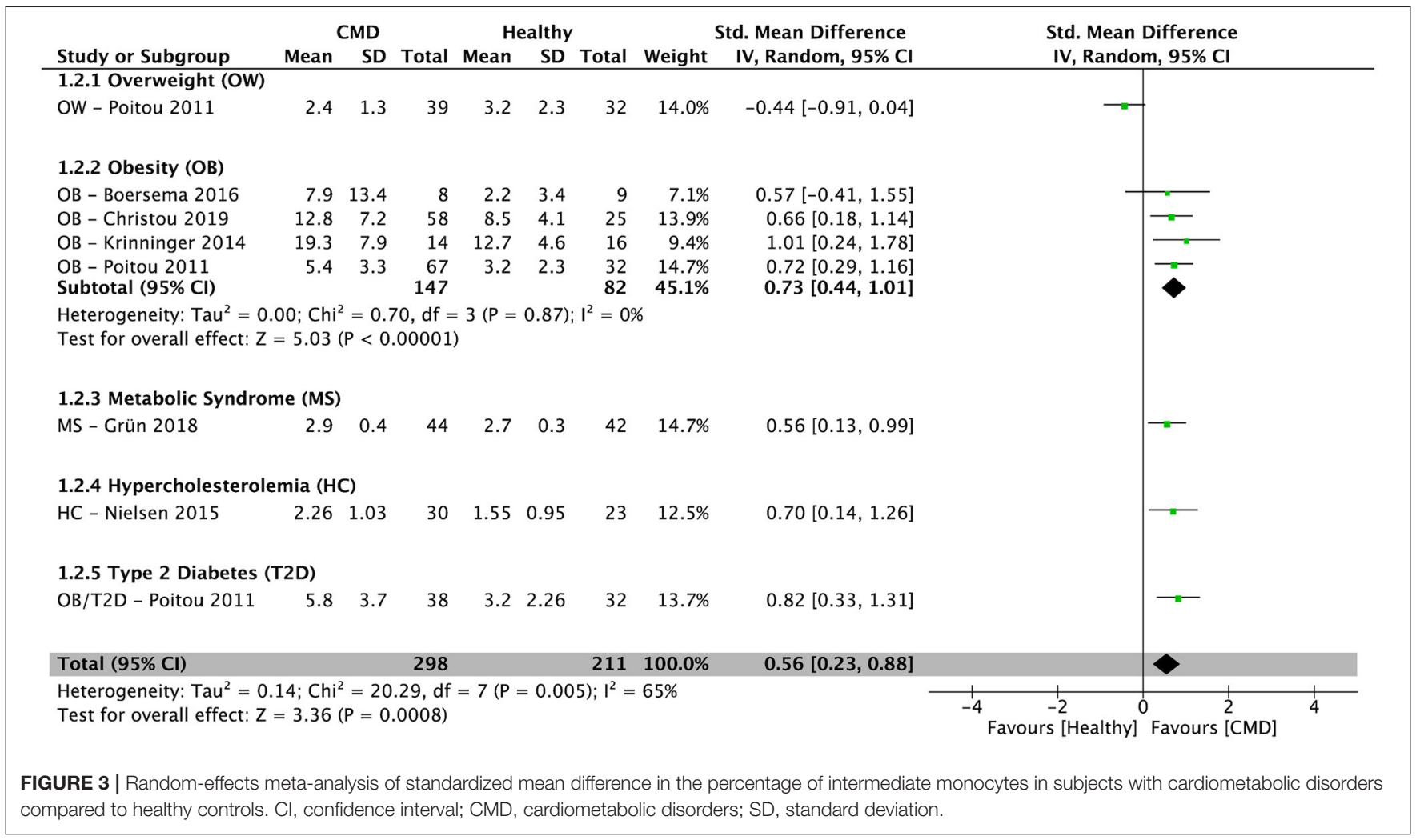

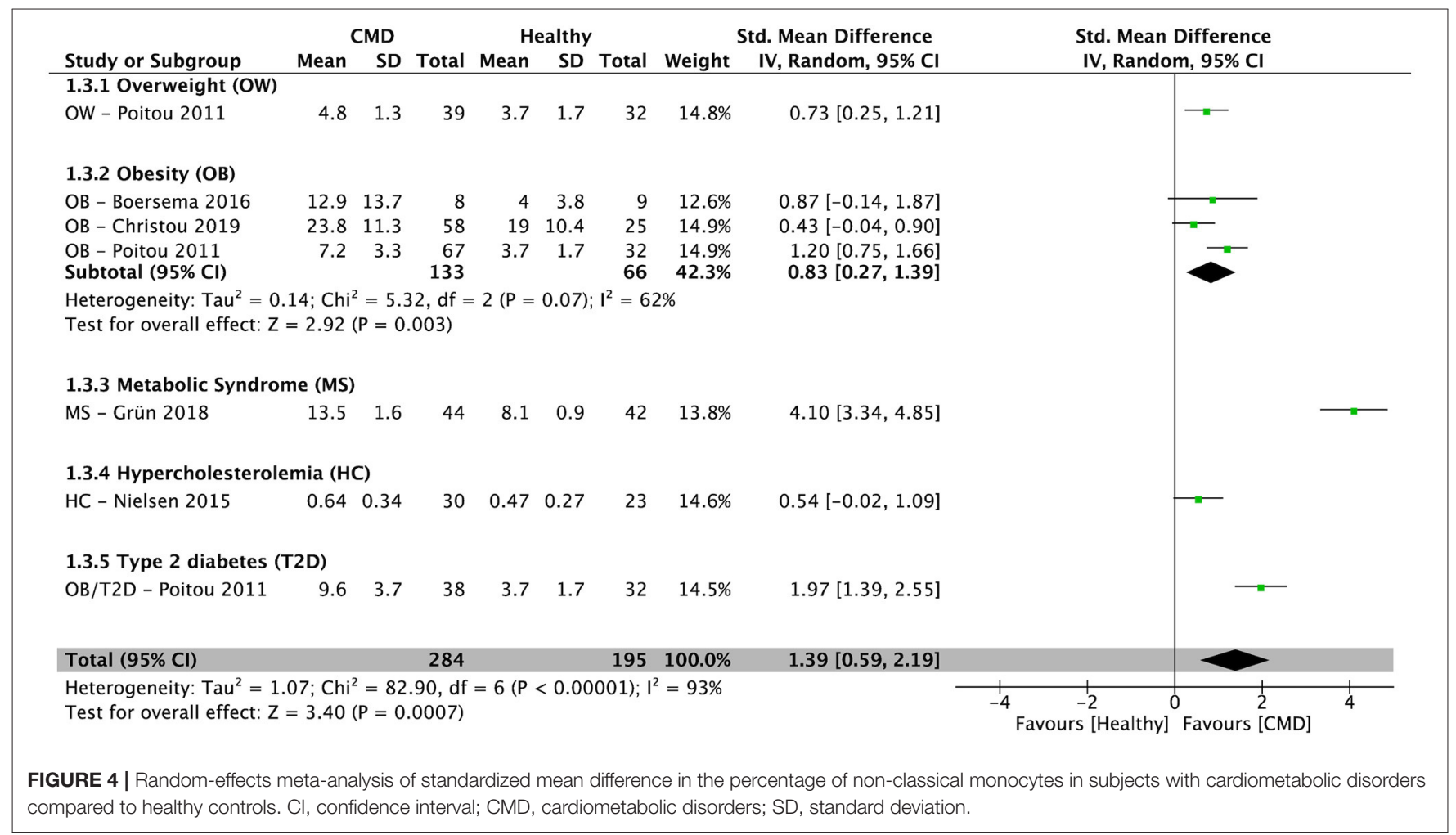

and/or NCM in subjects with cardiometabolic disorders (overweight/obesity, metabolic syndrome, hypercholesterolemia, and type 2 diabetes) compared to healthy controls. Moreover, we found that 11 out of 15 studies reported a higher percentage and number of IM and/or NCM in subjects with CVD (atherosclerosis, coronary artery/heart disease, chronic/acute 
heart failure, acute myocardial infarction and acute coronary syndrome) compared to healthy controls. In the meta-analysis, we demonstrated that subjects with cardiometabolic disorders had a significantly higher percentage of IM and NCM and a significantly lower percentage of CM compared to healthy controls. Collectively, results from both the systematic review and meta-analysis suggest that the distribution of monocytes may be altered resulting in a higher percentage and number of IM and NCM in subjects with cardiometabolic disorders and CVD. However, additional studies with larger sample sizes and more diverse populations are needed to better understand this relationship.

Monocytes play a crucial role in the pathology of atherosclerosis and CVD (59). In epidemiological and clinical studies, monocytosis is an independent risk factor for CVD (6062). However, our understanding of the role of monocyte subsets in the development of CVD is largely based on animal models of atherosclerosis and myocardial infarction $(63,64)$. Mouse $\mathrm{CM}\left(\mathrm{Grl}^{+} / \mathrm{Ly}-6 \mathrm{C}^{\text {high }}\right.$; $\mathrm{CD} 14^{++} \mathrm{CD} 16^{-}$homolog in humans) are recruited into the intima, differentiate into macrophages that phagocytose lipids and cholesterol derivatives, forming foam cells in the subintima, which ultimately contribute to the accumulation of fatty deposits (plaques) $(63,64)$. Mouse NCM (Gr1 ${ }^{-} /$Ly-6 Clow $^{\text {lo }}$ CD $14^{+} \mathrm{CD} 16^{++}$homolog in humans) are involved in scavenging the endothelium and clearing lipid derivatives, and dead and dying cells $(63,64)$. In humans, three distinct monocytes were defined in 2010 and includes a third subset called IM in addition to CM and NCM (16). Each monocyte subset appears to have distinct phenotypic and functional properties that may contribute differentially to inflammatory responses (16).

CM comprise the largest proportion of circulating monocytes (80-90\%) (65). Based on the proatherogenic function of CM observed in mouse models, they have been hypothesized to be the subset involved in the pathogenesis of CVD (64). In humans, CM highly express cell surface receptors that are involved in pathogen recognition, phagocytosis, and adhesion and migration into the vascular endothelium (17). In our systematic review, six out of eight studies quantifying the number of monocyte subsets reported a higher number of CM in subjects with CVD. However, despite the increase in total number of $\mathrm{CM}$, five out of 12 studies quantifying the percentage of monocyte subsets reported a lower percentage of CM in subjects with CVD. In addition, our metaanalysis demonstrated a significantly lower percentage of CM in subjects with obesity, metabolic syndrome, and type 2 diabetes compared to healthy controls. Combined these results suggests that despite a potential overall increase in the number of $\mathrm{CM}$, a shift in the distribution of monocyte subsets from CM to IM and/or NCM may occur in subjects with both cardiometabolic disorders and CVD. This shift may influence atherosclerotic risk or progression, and should be explored in future studies.

In humans, evidence to date suggests that IM and NCM account for $10-20 \%$ of circulating monocytes (65) and they may be linked to atherosclerosis and CVD. In vivo LPS challenge studies in humans demonstrate an expansion of IM and NCM $24 \mathrm{~h}$ after LPS injection ( $2 \mathrm{ng} / \mathrm{kg}$ body weight) in healthy subjects $(66,67)$, suggesting that IM and NCM IM and NCM respond acutely to a standardized low-grade inflammatory stimulus. IM produce and secrete high levels of proinflammatory cytokines IL-1 $\beta$, IL-6, and TNF- $\alpha$ upon LPS stimulation $(18,19,68)$. IM also play role in angiogenesis, antigen presentation, and proliferation and stimulation of T cells $(17,18)$. Our systematic review found that five out of six studies reported a higher percentage and number of IM in subjects with overweight/obesity $(33,34,36-38)$, one out of two studies reported a higher percentage of IM in subjects with hypercholesterolemia (42), but only one out of four studies reported higher percentage and number of IM in subjects with type 2 diabetes (34) compared to healthy controls. Our meta-analysis demonstrated a significantly higher percentage of IM in subjects with obesity, metabolic syndrome, hypercholesterolemia and type 2 diabetes compared to healthy controls. In addition, in the meta-analysis of correlation coefficients, we demonstrated a positive correlation between IM and CVD risk factors including BMI, fat mass, FBG, fasting insulin, HOMA-IR, TG and CRP. Moreover, previous studies report that weight loss after gastric bypass surgery in patients with obesity leads to a significant reduction in $\operatorname{IM}(34,69)$. Combined these finding suggest that an increase in IM is observed in subjects with cardiometabolic disorders, particularly those with obesity, and dyslipidemia and possibly those with hyperglycemia.

In addition to the relationship between IM and the previously discussed cardiometabolic disorders, emerging evidence suggest that an increase in IM may be observed in subjects with CVD. Two prospective cohort studies identified the number of IM as a positive predictor of major cardiovascular events in patients referred for elective coronary angiography $(n=951)(26)$ and in patients with chronic kidney disease $(n=438)$ (70). In our systematic review, we found that two studies reported a higher percentage of IM in subjects with atherosclerosis $(27,46)$, one study reported higher percentage and number of IM in subjects with acute heart failure (56), and two studies reported higher percentage and number of IM in patients with acute myocardial infarction $(52,53)$ compared to healthy controls. Although no correlation between IM and coronary artery/heart disease was reported, there were phenotypic changes in IM in these patients such as a higher percentage of MPA (49) [a sensitive indicator of monocyte inflammation (71)] and a higher expression of Tie2 (41) [an indicator of elevated proatherogenic activity of this monocyte subsets $(72,73)$ ] compared to healthy controls. Data from our systematic review and meta-analysis in combination with findings from other studies suggest that an elevated percentage of IM is observed in subjects with cardiometabolic disorders and CVD. Additional studies are warranted to determine if the percentage of IM are altered as a consequence of cardiometabolic dysfunction and/or CVD, and/or if the elevated percentage of IM contributes to the risk or progression of cardiometabolic disorders and/or CVD.

NCM patrol along the vascular endothelium and selectively detect damaged cells (74). However, conflicting results exists with some reports demonstrating an atheroprotective role while others report a proatherogenic role of NCM. In support of the atheroprotective role of $\mathrm{NCM}$, when $\mathrm{Nr}_{4} \mathrm{al}^{-/-}$mice that lack Ly6C $\mathrm{C}^{\text {lo }} \mathrm{NCM}$ are crossed with the atherogenic $\mathrm{ApoE}^{-/-}$ mice and fed a Western diet, they have a significant increase 
in atherosclerotic lesion size compared to $\mathrm{ApoE}^{-/-}$mice with functional NCM (75). Furthermore, when the bone marrow from $\mathrm{Nr} 4 \mathrm{a}^{-/-}$-deficient mice is transplanted into $\mathrm{Ldlr}^{-/-}$mice fed a high-fat diet, these mice develop a larger atherosclerotic lesion size compared to $\mathrm{Ldlr}^{-/}$mice transplanted with wildtype bone marrow (76). In addition, an expansion of Slan ${ }^{+}$ NCM, which are involved in efferocytosis, is reported in patients with coronary artery disease (77). This expand population of Slan ${ }^{+}$NCM in subjects with coronary artery disease may reflect a compensatory increase in NCM in response to vascular inflammation, which may suggest an atheroprotective role of NCM. In contrast, Ong et al. report that NCM produce higher basal levels of IL-1 $\beta$, IL-6, and TNF- $\alpha$ compared to CM (3), suggesting that NCM may contribute to chronic low-grade inflammation. Moreover, TLR8-induced secretion of IL-1 $\beta$ and CCL5 from NCM is higher in subjects with obesity compared to healthy controls (37), suggesting that obesity may enhance the inflammatory phenotype of NCM. Our meta-analysis demonstrated a higher percentage of NCM in subjects with overweight/obesity, metabolic syndrome, hypercholesterolemia and type 2 diabetes compared to healthy subjects. We also demonstrated a positive correlation between NCM and the CVD risk factors including BMI, fasting insulin and HOMAIR. In our systematic review, we found studies that reported an elevated percentage and number of NCM in subjects with obesity (three out of five studies) $(34,36,37)$, metabolic syndrome (two out of two studies) $(39,40)$, and type 2 diabetes (two out of four studies) $(34,44)$ compared to healthy controls. Moreover, we found studies that reported a higher percentage of NCM in subjects with coronary artery/heart disease (two out of seven studies), chronic/acute heart failure (three out of three studies), and acute myocardial infarction (one out of three studies) compared to healthy controls. Thus, our results suggest that an elevation in NCM may be observed in subjects with cardiometabolic disorders and some forms of CVD. It is plausible that the presence of NCM in healthy subjects may have an atheroprotective role by patrolling vascular endothelium and detecting damaged cells, but their inflammatory phenotype may be enhanced in those individuals with cardiometabolic disorders and CVD. Future studies are needed to explore the relationship between these observations.

Previous studies demonstrate that inherited (e.g., ethnicity, gender, and age) and environmental (e.g., diet and exercise) factors can influence the distribution of monocyte subsets [reviewed in (78)]. For example, Caucasian populations are reported to have a higher percentage of $\mathrm{CM}$ and a lower percentage of NCM compared to African populations (79). Additionally, women are reported to have a lower percentage of circulating NCM compared to men (80). Older adults have a decreased percentage of $\mathrm{CM}$ and an increased percentage of IM and NCM (80). Consumption of a single high-fat meal (40) and overall diet quality (81) alters the distribution of NCM and IM, respectively. Lastly, acute bout of exercise (82-85), as well as chronic exercise training (86) alters the distribution of monocyte subsets. Thus, inherited and environmental factors may be confounding factors that influence the distribution of monocyte subsets.
A major strength of our review is that this is the first systematic review and meta-analysis to assess the change in the distribution of monocyte subsets in individuals with cardiometabolic disorders and CVD compared to healthy individuals. This systematic review implemented a search strategy which was comprehensive and complete. Examination of funnel plots revealed minimal evidence of publication bias. Moreover, the meta-analysis had low to moderate heterogeneity observed among studies. Studies in this review include subjects with a mean/median age (20-70 years) and include both male and female subjects, representing a fairly heterogeneous population. However, a limitation of this systematic review is that many studies included in this systematic review did not adjust the outcomes (the percentage and number of monocyte subsets) for potential confounding factors [with the exception of two studies that adjusted monocyte outcomes for age and gender $(34,54)]$. Additionally, many of the studies included in the review had a small sample size, and a small number of studies are included in both the systematic review and meta-analysis. Thus, these results should be interpreted with caution. Lastly, variation may exist in defining monocyte subsets using flow cytometric analyses which could significantly impact interpretation of our findings (78).

In conclusion, we demonstrated that a shift in the distribution of monocyte subsets from CM toward IM and NCM may occur in individuals with cardiometabolic disorders and CVD. However, there is insufficient evidence to draw conclusions as to the underlying causality of this association. Future longitudinal studies are needed to demonstrate a causal relationship between the shift in the distribution of monocyte subsets and the risk and/or progression of cardiometabolic disorders and/or CVD.

\section{DATA AVAILABILITY STATEMENT}

The original contributions generated in the study are included in the article/Supplementary Material, further inquiries can be directed to the corresponding author/s.

\section{AUTHOR CONTRIBUTIONS}

EO and CR designed the research, conducted the research, and collected data. EO, MN, and CR participated in data analysis and interpretation and wrote the paper. CR had primary responsibility for the final content. All authors contributed to the article and approved the submitted version.

\section{FUNDING}

This study was supported by American Heart Association (AHA) Predoctoral Fellowship 20PRE35090014 (EO), and by National Center for Advancing Translational Sciences at NIH through Grant 1UL1TR002014-01 (EO and CR). AHA and NIH had no 
role in study design, data analysis, data interpretation, or writing of the article.

\section{ACKNOWLEDGMENTS}

The corresponding author had full access to all the data in the study and had final responsibility for the decision to submit for publication. We thank Dr. Christina L. Wissinger, a health sciences librarian at the Pennsylvania State

\section{REFERENCES}

1. Roth GA, Johnson C, Abajobir A, Abd-Allah F, Abera SF, Abyu G, et al. Global, regional, and national burden of cardiovascular diseases for 10 causes, 1990 to 2015. J Am Coll Cardiol. (2017) 70:1-25. doi: 10.1016/j.jacc.2017.04.052

2. Virani SS, Alonso A, Benjamin EJ, Bittencourt MS, Callaway CW, Carson AP, et al. Heart disease and stroke statistics-2020 update: a report from the American Heart Association. Circulation. (2020) 141:E139-596. doi: 10.1161/CIR.0000000000000757

3. Ong S-M, Hadadi E, Dang T-M, Yeap W-H, Tan CT-Y, Ng T-P, et al. The pro-inflammatory phenotype of the human non-classical monocyte subset is attributed to senescence. Cell Death Dis. (2018) 9:1-12. doi: 10.1038/s41419-018-0327-1

4. Bentzon JF, Otsuka F, Virmani R, Falk E. Mechanisms of plaque formation and rupture. Circ Res. (2014) 114:1852-66. doi: 10.1161/CIRCRESAHA.114.302721

5. Lala A, Desai AS. The role of coronary artery disease in heart failure. Heart Fail Clin. (2014) 10:353-65. doi: 10.1016/j.hfc.2013.10.002

6. Kim W, Kim EJ. Heart failure as a risk factor for stroke. J Stroke. (2018) 20:33. doi: 10.5853/jos.2017.02810

7. Mathieu P, Pibarot P, Després J-P. Metabolic syndrome: the danger signal in atherosclerosis. Vasc Health Risk Manag. (2006) 2:285. doi: 10.2147/vhrm.2006.2.3.285

8. Aboonabi A, Rose'Meyer R, Singh I. The association between metabolic syndrome components and the development of atherosclerosis. J Hum Hypertens. (2019) 33:1-12. doi: 10.1038/s41371-019-0273-0

9. Koenig W, Löwel H, Baumert J, Meisinger C. C-reactive protein modulates risk prediction based on the Framingham Score: implications for future risk assessment: results from a large cohort study in southern Germany. Circulation. (2004) 109:1349-53. doi: 10.1161/01.CIR.0000120707.98922.E3

10. Pai JK, Pischon T, Ma J, Manson JE, Hankinson SE, Joshipura K, et al. Inflammatory markers and the risk of coronary heart disease in men and women. N Engl J Med. (2004) 351:2599-610. doi: 10.1056/NEJMoa040967

11. Albert CM, Ma J, Rifai N, Stampfer MJ, Ridker PM. Prospective study of C-reactive protein, homocysteine, and plasma lipid levels as predictors of sudden cardiac death. Circulation. (2002) 105:2595-9. doi: 10.1161/01.CIR.0000017493.03108.1C

12. Hotamisligil GS. Inflammation and metabolic disorders. Nature. (2006) 444:860-7. doi: 10.1038/nature05485

13. Flynn MC, Pernes G, Lee MKS, Murphy AJ, Nagareddy PR. Monocytes, macrophages and metabolic disease in atherosclerosis. Front Pharmacol. (2019) 10:666. doi: 10.3389/fphar.2019.00666

14. Singh RB, Mengi SA, Xu Y-J, Arneja AS, Dhalla NS. Pathogenesis of atherosclerosis: a multifactorial process. Exp Clin Cardiol. (2002) 7:40.

15. Guilliams M, Ginhoux F, Jakubzick C, Naik SH, Onai N, Schraml BU, et al. Dendritic cells, monocytes and macrophages: a unified nomenclature based on ontogeny. Nat Rev Immunol. (2014) 14:571. doi: 10.1038/nri3712

16. Ziegler-Heitbrock L, Ancuta P, Crowe S, Dalod M, Grau V, Hart DN, et al. Nomenclature of monocytes and dendritic cells in blood. Blood. (2010) 116:e74-80. doi: 10.1182/blood-2010-02-258558

17. Zawada AM, Rogacev KS, Rotter B, Winter P, Marell RR, Fliser D, et al. SuperSAGE evidence for CD14++CD16+ monocytes as a third monocyte subset. Blood. (2011) 118:e50-61. doi: 10.1182/blood-2011-01-326827
University-University Park campus for the support on building search strategy.

\section{SUPPLEMENTARY MATERIAL}

The Supplementary Material for this article can be found online at: https://www.frontiersin.org/articles/10.3389/fcvm. 2021.640124/full\#supplementary-material

18. Wong KL, Tai JJ-Y, Wong W-C, Han H, Sem X, Yeap W-H, et al Gene expression profiling reveals the defining features of the classical intermediate, and nonclassical human monocyte subsets. Blood. (2011) 118:e16-31. doi: 10.1182/blood-2010-12-326355

19. Boyette LB, Macedo C, Hadi K, Elinoff BD, Walters JT, Ramaswami B, et al. Phenotype, function, and differentiation potential of human monocyte subsets. PLoS ONE. (2017) 12:e0176460. doi: 10.1371/journal.pone.0176460

20. Kränkel N, Kuschnerus K, Madeddu P, Lüscher TF, Landmesser U. A novel flow cytometry-based assay to study leukocyte-endothelial cell interactions in vitro. Cytometry A. (2011) 79:256-62. doi: 10.1002/cyto.a.21043

21. Connaughton EP, Naicker S, Hanley SA, Slevin SM, Eykelenboom JK, Lowndes NF, et al. Phenotypic and functional heterogeneity of human intermediate monocytes based on HLA-DR expression. Clin Transl Immunol. (2018) 96:742-58. doi: 10.1111/imcb.12032

22. Rogacev KS, Seiler S, Zawada AM, Reichart B, Herath E, Roth D, et al. CD14++ CD16+ monocytes and cardiovascular outcome in patients with chronic kidney disease. Eur Heart J. (2011) 32:84-92. doi: 10.1093/eurheartj/ehq371

23. Carlin LM, Stamatiades EG, Auffray C, Hanna RN, Glover L, VizcayBarrena G, et al. Nr4al-dependent Ly6Clow monocytes monitor endothelial cells and orchestrate their disposal. Cell. (2013) 153:362-75. doi: 10.1016/j.cell.2013.03.010

24. Quintar A, McArdle S, Wolf D, Marki A, Ehinger E, Vassallo M, et al. Endothelial protective monocyte patrolling in large arteries intensified by western diet and atherosclerosis. Circ Res. (2017) 120:1789-99. doi: 10.1161/CIRCRESAHA.117.310739

25. Marcovecchio PM, Thomas GD, Mikulski Z, Ehinger E, Mueller KA, Blatchley A, et al. Scavenger receptor CD36 directs nonclassical monocyte patrolling along the endothelium during early atherogenesis. Arterioscler Thromb Vasc Biol. (2017) 37:2043-52. doi: 10.1161/ATVBAHA.117.309123

26. Rogacev KS, Cremers B, Zawada AM, Seiler S, Binder N, Ege P, et al. CD14++ CD16+ monocytes independently predict cardiovascular events: a cohort study of 951 patients referred for elective coronary angiography. J Am Coll Cardiol. (2012) 60:1512-20. doi: 10.1016/j.jacc.2012.07.019

27. Williams H, Cassorla G, Pertsoulis N, Patel V, Vicaretti M, Marmash N, et al. Human classical monocytes display unbalanced Ml/M2 phenotype with increased atherosclerotic risk and presence of disease. Int Angiol. (2017) 36:145-55. doi: 10.23736/S0392-9590.16.03661-0

28. Moher D, Shamseer L, Clarke M, Ghersi D, Liberati A, Petticrew M, et al. Preferred reporting items for systematic review and meta-analysis protocols (PRISMA-P) 2015 statement. Syst Rev. (2015) 4:1. doi: 10.1186/2046-4053-4-1

29. The NIH National Heart, Lung, and Blood Institute (NHLBI) Quality Assessment Tool. Available online at: https://www.nhlbi.nih.gov/healthtopics/study-quality-assessment-tools (accessed October 1, 2020).

30. Sterne JA, Hernán MA, Reeves BC, Savović J, Berkman ND, Viswanathan $\mathrm{M}$, et al. ROBINS-I: a tool for assessing risk of bias in non-randomised studies of interventions. BMJ. (2016) 355:i4919. doi: 10.1136/bm j.i4919

31. Hozo SP, Djulbegovic B, Hozo I. Estimating the mean and variance from the median, range, and the size of a sample. BMC Med Res Methodol. (2005) 5:13. doi: 10.1186/1471-2288-5-13

32. Review Manager (RevMan) (Computer program). Version 5.3. Copenhagen: The Nordic Cochrane Centre, The Cochrane Collaboration (2014). 
33. Friedrich K, Sommer M, Strobel S, Thrum S, Bluher M, Wagner U, et al. Perturbation of the monocyte compartment in human obesity. Front Immunol. (2019) 10:1874. doi: 10.3389/fimmu.2019.01874

34. Poitou C, Dalmas E, Renovato M, Benhamo V, Hajduch F, Abdennour M, et al. CD14(dim)CD16(+) and CD14(+)CD16(+) monocytes in obesity and during weight loss relationships with fat mass and subclinical atherosclerosis. Arterioscler Thromb Vasc Biol. (2011) 31:2322-U372. doi: 10.1161/ATVBAHA.111.230979

35. Boersema GSA, Utomo L, Bayon Y, Kops N, van der Harst E, Lange JF, et al. Monocyte subsets in blood correlate with obesity related response of macrophages to biomaterials in vitro. Biomaterials. (2016) 109:32-9. doi: 10.1016/j.biomaterials.2016.09.009

36. Christou KA, Christou GA, Karamoutsios A, Vartholomatos G, Gartzonika $\mathrm{K}$, Tsatsoulis A, et al. Metabolically healthy obesity is characterized by a proinflammatory phenotype of circulating monocyte subsets. Metab Syndr Relat Disord. (2019) 17:259-65. doi: 10.1089/met.2018.0132

37. Devêvre EF, Renovato-Martins $M$, Clément $K$, Sautès-Fridman C, Cremer I, Poitou C. Profiling of the three circulating monocyte subpopulations in human obesity. J Immunol. (2015) 194:3917-23. doi: 10.4049/jimmunol.1402655

38. Krinninger P, Ensenauer R, Ehlers K, Rauh K, Stoll J, Krauss-Etschmann S, et al. Peripheral monocytes of obese women display increased chemokine receptor expression and migration capacity. J Clin Endocrinol Metab. (2014) 99:2500-9. doi: 10.1210/jc.2013-2611

39. Grün JL, Manjarrez-Reyna AN, Gómez-Arauz AY, Leon-Cabrera S, Rückert F, Fragoso JM, et al. High-density lipoprotein reduction differentially modulates to classical and nonclassical monocyte subpopulations in metabolic syndrome patients and in LPS-stimulated primary human monocytes. J Immunol Res. (2018) 2018:2737040. doi: 10.1155/2018/2737040

40. Khan IM, Pokharel Y, Dadu RT, Lewis DE, Hoogeveen RC, Wu HZ, et al. Postprandial monocyte activation in individuals with metabolic syndrome. $J$ Clin Endocrinol Metab. (2016) 101:4195-204. doi: 10.1210/jc.2016-2732

41. Jaipersad AS, Shantsila A, Lip GYH, Shantsila E. Expression of monocyte subsets and angiogenic markers in relation to carotid plaque neovascularization in patients with pre-existing coronary artery disease and carotid stenosis. Ann Med. (2014) 46:530-8. doi: 10.3109/07853890.2014.931101

42. Nielsen MH, Irvine H, Vedel S, Raungaard B, Beck-Nielsen H, Handberg A. Elevated atherosclerosis-related gene expression, monocyte activation and microparticle-release are related to increased lipoprotein-associated oxidative stress in familial hypercholesterolemia. PLOS ONE. (2015) 10:121516. doi: 10.1371/journal.pone.0121516

43. von Scholten BJ, Rosendahl A, Hasbak P, Bergholdt R, Kjaer A, Rossing P, et al. Impaired coronary microcirculation in type 2 diabetic patients is associated with elevated circulating regulatory $\mathrm{T}$ cells and reduced number of IL21R(+) T cells. Cardiovasc Diabetol. (2016) 15:67. doi: 10.1186/s12933-0160378-5

44. Zaharieva E, Vikentieva E, Andreeva R, Popova D, Tsakove A, Kamenov Z. Elevated CD163 expression on CD14++CD16+ monocytes in type 2 diabetes. Diabetes Stoffwech H. (2017) 26:271-6.

45. Valtierra-Alvarado M, Delgado JC, Ramírez-Talavera S, Lugo-Villarino G, Dueñas-Arteaga F, Lugo-Sánchez A, et al. Type 2 diabetes mellitus metabolic control correlates with the phenotype of human monocytes and monocyte-derived macrophages. J Diabetes Complications. (2020) 34:107708. doi: 10.1016/j.jdiacomp.2020.107708

46. Chelombitko MA, Shishkina VS, Ilyinskaya OP, Kaminnyi AI, Pavlunina TO, Samovilova NN, et al. A cytofluorometric study of membrane rafts in human monocyte subsets in atherosclerosis. Acta Nat. (2014) 6:80-8. doi: 10.32607/20758251-2014-6-4-80-88

47. Xiang Y, Liang B, Zhang X, Zheng F. Lower HDL-C levels are associated with higher expressions of CD16 on monocyte subsets in coronary atherosclerosis. Int J Med Sci. (2020) 17:2171. doi: 10.7150/ijms.47998

48. Czepluch FS, Kuschicke H, Dellas C, Riggert J, Hasenfuss G, Schafer K. Atheroprotective kruppel-like factor 4 is downregulated in monocyte subsets of patients with coronary artery disease. Thromb Haemost. (2013) 110:1080-2. doi: 10.1160/TH13-05-0367

49. Czepluch FS, Kuschicke H, Dellas C, Riggert J, Hasenfuss G, Schafer $\mathrm{K}$. Increased proatherogenic monocyte-platelet cross-talk in monocyte subpopulations of patients with stable coronary artery disease. J Intern Med. (2014) 275:144-54. doi: 10.1111/joim.12145

50. Shantsila E, Tapp LD, Wrigley BJ, Pamukcu B, Apostolakis S, Montoro-Garcia $\mathrm{S}$, et al. Monocyte subsets in coronary artery disease and their associations with markers of inflammation and fibrinolysis. Atherosclerosis. (2014) 234:410. doi: 10.1016/j.atherosclerosis.2014.02.009

51. Tallone T, Turconi G, Soldati G, Pedrazzini G, Moccetti T, Vassalli G. Heterogeneity of human monocytes: an optimized four-color flow cytometry protocol for analysis of monocyte subsets. J Cardiovasc Transl Res. (2011) 4:211-9. doi: 10.1007/s12265-011-9256-4

52. Tapp L, Shantsila E, Wrigley B, Pamukcu B, Lip G. The CD14++ CD16+ monocyte subset and monocyte-platelet interactions in patients with STelevation myocardial infarction. J Thromb Haemost. (2011) 10:1231-41. doi: 10.1111/j.1538-7836.2011.04603.x

53. Zhou X, Liu X-L, Ji W-J, Liu J-X, Guo Z-Z, Ren D, et al. The kinetics of circulating monocyte subsets and monocyte-platelet aggregates in the acute phase of ST-elevation myocardial infarction: associations with 2-year cardiovascular events. Medicine. (2016) 95:e3466. doi: 10.1097/MD.0000000000003466

54. Amir O, Spivak I, Lavi I, Rahat MA. Changes in the monocytic subsets CD14(dim)CD16(+) and CD14(++)CD16(-) in chronic systolic heart failure patients. Mediators Inflamm. (2012) 2012:616384. doi: 10.1155/2012/616384

55. Van Craenenbroeck AH, Van Ackeren K, Hoymans VY, Roeykens J, Verpooten GA, Vrints CJ, et al. Acute exercise-induced response of monocyte subtypes in chronic heart and renal failure. Mediators Inflamm. (2014) 2014:216534. doi: 10.1155/2014/216534

56. Goonewardena SN, Stein AB, Tsuchida RE, Rattan R, Shah D, Hummel SL. Monocyte subsets and inflammatory cytokines in acute decompensated heart failure. J Card Fail. (2016) 22:358-65. doi: 10.1016/j.cardfail.2015.12.014

57. Kazimierczyk E, Eljaszewicz A, Zembko P, Tarasiuk E, Rusak M, KulczynskaPrzybik A, et al. The relationships among monocyte subsets, miRNAs and inflammatory cytokines in patients with acute myocardial infarction. Pharmacol Rep. (2019) 71:73-81. doi: 10.1016/j.pharep.2018.09.007

58. Zhu L, Yin YG, Zhou RF, Lin J, Li JM, Ye J. Changes of monocyte subsets in patients with acute coronary syndrome and correlation with myocardial injury markers. Int J Clin Exp Pathol. (2015) 8:7266-71.

59. Honold L, Nahrendorf M. Resident and monocyte-derived macrophages in cardiovascular disease. Circ Res. (2018) 122:113-27. doi: 10.1161/CIRCRESAHA.117.311071

60. Waterhouse DF, Cahill RA, Sheehan F, McCreery C. Prediction of calculated future cardiovascular disease by monocyte count in an asymptomatic population. Vasc Health Risk Manag. (2008) 4:177. doi: 10.2147/VHRM.S2240

61. Lassale C, Curtis A, Abete I, van der Schouw YT, Verschuren WM, Lu Y. Elements of the complete blood count associated with cardiovascular disease incidence: findings from the EPIC-NL cohort study. Sci Rep. (2018) 8:1-11. doi: 10.1038/s41598-018-21661-x

62. Pinto EM, Huppert FA, Morgan K, Cfas M, Brayne C. Neutrophil counts, monocyte counts and cardiovascular disease in the elderly. Exp Gerontol. (2004) 39:615-9. doi: 10.1016/j.exger.2003.12.011

63. Hilgendorf I, Swirski FK. Making a difference: monocyte heterogeneity in cardiovascular disease. Curr Atheroscler Rep. (2012) 14:450-9. doi: $10.1007 / \mathrm{s} 11883-012-0274-8$

64. Woollard KJ, Geissmann F. Monocytes in atherosclerosis: subsets and functions. Nat Rev Cardiol. (2010) 7:77. doi: 10.1038/nrcardio.2009.228

65. Ziegler-Heitbrock L, Hofer TP. Toward a refined definition of monocyte subsets. Front Immunol. (2013) 4:23. doi: 10.3389/fimmu.2013.00023

66. Tak T, Van Groenendael R, Pickkers P, Koenderman L. Monocyte subsets are differentially lost from the circulation during acute inflammation induced by human experimental endotoxemia. J Innate Immun. (2017) 9:464-74. doi: $10.1159 / 000475665$

67. Thaler B, Hohensinner P, Krychtiuk K, Matzneller P, Koller L, Brekalo M, et al. Differential in vivo activation of monocyte subsets during low-grade inflammation through experimental endotoxemia in humans. Sci Rep. (2016) 6:30162. doi: 10.1038/srep30162

68. Hadadi E, Zhang B, BaidŽajevas K, Yusof N, Puan KJ, Ong SM, et al. Differential IL-1 $\beta$ secretion by monocyte subsets is regulated by Hsp27 through modulating mRNA stability. Sci Rep. (2016) 6:39035. doi: $10.1038 /$ srep39035 
69. Chen H, Qian L, Lv Q, Yu J, Wu W, Qian H. Change in gut microbiota is correlated with alterations in the surface molecule expression of monocytes after Roux-en-Y gastric bypass surgery in obese type 2 diabetic patients. Am J Transl Res. (2017) 9:1243.

70. Rogacev KS, Zawada AM, Emrich I, Seiler S, Böhm M, Fliser D, et al. Lower Apo A-I and lower HDL-C levels are associated with higher intermediate CD14++ CD16+ monocyte counts that predict cardiovascular events in chronic kidney disease. Arterioscler Thromb Vasc Biol. (2014) 34:2120-7. doi: 10.1161/ATVBAHA.114.304172

71. Allen N, Barrett TJ, Guo Y, Nardi M, Ramkhelawon B, Rockman CB, et al. Circulating monocyte-platelet aggregates are a robust marker of platelet activity in cardiovascular disease. Atherosclerosis. (2019) 282:11-8. doi: 10.1016/j.atherosclerosis.2018.12.029

72. Murdoch C, Tazzyman S, Webster S, Lewis CE. Expression of Tie-2 by human monocytes and their responses to angiopoietin-2. J Immunol. (2007) 178:7405-11. doi: 10.4049/jimmunol.178.11.7405

73. Venneri MA, Palma MD, Ponzoni M, Pucci F, Scielzo C, Zonari E, et al. Identification of proangiogenic TIE2-expressing monocytes (TEMs) in human peripheral blood and cancer. Blood. (2007) 109:5276-85. doi: 10.1182/blood-2006-10-053504

74. Cros J, Cagnard N, Woollard K, Patey N, Zhang SY, Senechal B, et al. Human CD14dim monocytes patrol and sense nucleic acids and viruses via TLR7 and TLR8 receptors. Immunity. (2010) 33:375-86. doi: 10.1016/j.immuni.2010.08.012

75. Hanna RN, Shaked I, Hubbeling HG, Punt JA, Wu R, Herrley E, et al. NR4A1 (Nur77) deletion polarizes macrophages toward an inflammatory phenotype and increases atherosclerosis. Circ Res. (2012) 110:416-27. doi: 10.1161/CIRCRESAHA.111.253377

76. Hamers AA, Vos M, Rassam F, Marinković G, Kurakula K, van Gorp PJ, et al. Bone marrow-specific deficiency of nuclear receptor Nur77 enhances atherosclerosis. Circ Res. (2012) 110:428-38. doi: 10.1161/CIRCRESAHA.111.260760

77. Hamers AA, Dinh HQ, Thomas GD, Marcovecchio P, Blatchley A, Nakao CS, et al. Human monocyte heterogeneity as revealed by highdimensional mass cytometry. Arterioscler Thromb Vasc Biol. (2019) 39:25-36. doi: 10.1161/ATVBAHA.118.311022

78. Patel AA, Yona S. Inherited and environmental factors influence human monocyte heterogeneity. Front Immunol. (2019) 10:2581. doi: 10.3389/fimmu.2019.02581

79. Appleby LJ, Nausch N, Midzi N, Mduluza T, Allen JE, Mutapi F. Sources of heterogeneity in human monocyte subsets. Immunol Lett. (2013) 152:32-41. doi: 10.1016/j.imlet.2013.03.004
80. Hearps AC, Martin GE, Angelovich TA, Cheng WJ, Maisa A, Landay $\mathrm{AL}$, et al. Aging is associated with chronic innate immune activation and dysregulation of monocyte phenotype and function. Aging Cell. (2012) 11:867-75. doi: 10.1111/j.1474-9726.2012.00851.x

81. Dias JA, Wirfält E, Drake I, Gullberg B, Hedblad B, Persson M, et al. A high quality diet is associated with reduced systemic inflammation in middle-aged individuals. Atherosclerosis. (2015) 238:38-44. doi: 10.1016/j.atherosclerosis.2014.11.006

82. Steppich B, Dayyani F, Gruber R, Lorenz R, Mack M, Ziegler-Heitbrock HLM. Selective mobilization of CD14+CD16+ monocytes by exercise. Am J Physiol Cell Physiol. (2000) 279:C578-86. doi: 10.1152/ajpcell.2000.279.3.C578

83. Shantsila E, Tapp LD, Wrigley BJ, Montoro-Garcia S, Ghattas A, Jaipersad A, et al. The effects of exercise and diurnal variation on monocyte subsets and monocyte-platelet aggregates. Eur J Clin Invest. (2012) 42:832-9. doi: 10.1111/j.1365-2362.2012.02656.x

84. Slusher AL, Zúñiga TM, Acevedo EO. Maximal exercise alters the inflammatory phenotype and response of mononuclear cells. Med Sci Sports Exerc. (2018) 50:675-83. doi: 10.1249/MSS.00000000000 01480

85. Graff RM, Kunz HE, Agha NH, Baker FL, Laughlin M, Bigley AB, et al. $\beta(2)$-Adrenergic receptor signaling mediates the preferential mobilization of differentiated subsets of CD8+ T-cells, NK-cells and non-classical monocytes in response to acute exercise in humans. Brain Behav Immun. (2018) 74:14353. doi: 10.1016/j.bbi.2018.08.017

86. Dorneles GP, da Silva I, Boeira MC, Valentini D, Fonseca SG, Dal Lago P, et al. Cardiorespiratory fitness modulates the proportions of monocytes and T helper subsets in lean and obese men. Scand J Med Sci Sports. (2019) 29:1755-65. doi: 10.1111/sms.13506

Disclaimer: The content is solely the responsibility of the authors and does not necessarily represent the official views of AHA and NIH.

Conflict of Interest: The authors declare that the research was conducted in the absence of any commercial or financial relationships that could be construed as a potential conflict of interest.

Copyright (c) $2021 \mathrm{Oh}, \mathrm{Na}$ and Rogers. This is an open-access article distributed under the terms of the Creative Commons Attribution License (CC BY). The use, distribution or reproduction in other forums is permitted, provided the original author(s) and the copyright owner(s) are credited and that the original publication in this journal is cited, in accordance with accepted academic practice. No use, distribution or reproduction is permitted which does not comply with these terms. 